\title{
Study on Performance of Different Fodder Crops under Low Cost Green House Hydroponic Fodder Production System
}

\author{
A.Krishna Murthy ${ }^{1}$, G.Dhanalakshmi ${ }^{2}$, Kalyan Chakravarthy ${ }^{3}$ \\ ${ }^{1}$ Scientist (AH), SHE \& CS Krishi Vigyan Kendra, Yagantipalle, Kurnool Dist. A.P., India \\ ${ }^{2}$ Senior Scientist \& Head, SHE \& CS Krishi Vigyan Kendra, Yagantipalle, Kurnool Dist. A.P., India \\ ${ }^{3}$ Assistant Professor, ILFC, College of Veterinary Science, Proddatur, India
}

\begin{abstract}
Hydroponics play most significant role in augmenting fodder shortage and helps for dairy production efficiently. A study was conducted to assess the performance and suitability of different crops under low cost green house hydroponic fodder production unit at SHE\&CS Krishi Vigyan Kendra, Yagantipalle. Four varieties of cereals grains and four verities of Pulses were tested. One kilogram grain each of the variety was soaked for 12 hours in water for sprouting in air tight condition for 36 hours. The sprouted seed was spread in trays of size $2.5 \mathrm{ft} X 1.5 \mathrm{ft}$ and kept in the Hydroponic Unit. Automatic sprinkling of water was managed by cyclic timer. Chemical fertilizer was not used. Data on sprouted seed weight and weight of biomass after 5 days was recorded using electronic weighing balance. The high biomass yield after 5days in cereals was recorded in Bajra followed by sorghum, Barley and Maize. Among pulses Pillipesara yielded highest weight followed by Cowpea, Lucerne and Horse gram. Highest plant height among cereals was recorded in Barley and cowpea in pulses. The difference among all the varieties in respect of biomass yield and plant height was found to be significant. Negative correlation was found between plant height and biomass yield.
\end{abstract}

Keywords- Low cost hydroponics, Fodder yield, hydroponic fodder production system.

\section{INTRODUCTION}

Green fodder plays a vital role in production and reproduction performance of dairy animals. Unavailability of land, resources and labour requirement are the major constraints faced by dairy farmers. Non availability of quality fodder round the year is major limitation for sustainable dairy farming (Naik et al, 2015). Fodder shortages are continuously hindering the milk production in these parts of arid region. To overcome this problem hydroponics is an alternative for successful feeding of dairy animals. Hydroponic fodder can be produced in low cost green houses (Naik, 2015). Maize and barley are the most common fodders which can be successfully grown under hydroponics. The present experiment was conducted to assess the growth of different pulse and cereal fodder crops under low cost green house type hydroponic unit.

\section{MATERIALS AND METHOD}

Four varieties of cereal grains viz., Maize (T1), Sorghum (T2), Bajra (T3), Barley (T4), and four verities of Pulses viz., Cowpea (T5), Lucerne (T6), Horse Gram (T7), PilliPesara (T8) were tested. One kilogram grain in each of the variety was soaked for 12 hours in water for sprouting in air tight condition for 36 hours. The sprouted seed was spread in U.V. stabilized plastic trays of size $2.5 \mathrm{ft} X 1.5 \mathrm{ft}$ and kept in the Hydroponic Unit. Automatic sprinkling of water was managed by cyclic timer. Chemical fertilizer was not used. Data on sprouted seed weight and weight of biomass after 7 days was recorded using electronic weighing balance and plant height was recorded using measuring scale. The data was statistically analyzed for its significance.

\section{RESULTS AND DISCUSSION}

Biomass yield:

The data recorded on the biomass yield of different cereal and pulse grains are given in table1. The data revealed that more weight of sprouted seed of cereals was observed in Bajra (2.17kg) followed by, sorghum $(2.04 \mathrm{~kg})$, Barley $(1.98 \mathrm{~kg})$, Maize $(1.08 \mathrm{Kg})$. In pulses high sprouted seed weight observed in Cowpea $(3.45 \mathrm{~kg})$ followed by Pillipesara $(3.26 \mathrm{~kg})$, Lucerne $(3.22 \mathrm{Kg})$ and Horse gram $(2.88 \mathrm{~kg})$. Significant and positive correlation between sprout weight and biomass yield was observed among all. 
The high biomass yield after 5days in cereals was recorded in Bajra $(6.37 \mathrm{~kg})$ followed by sorghum $(6.1 \mathrm{~kg})$, Barley $(5.06 \mathrm{~kg})$ and Maize $(4.82 \mathrm{~kg})$. Among pulses Pillipesara $(7.58 \mathrm{~kg})$ yielded highest weight followed by Cowpea $(7.2 \mathrm{~kg})$, Lucerne $(7.09 \mathrm{~kg})$ and Horse gram $(5.85 \mathrm{~kg})$. The difference $(\mathrm{P}>0.05)$ among all the varieties in respect of biomass yield was found to be significant. Naik et al (2015) reported fresh yield of $8-10 \mathrm{~kg}$ from one $\mathrm{kg}$ locally grown maize in 7-10 days under low cost devises. Brunean M.M. et al (2016) reported one kilogram of barley seeds provide 2.31 to $4.89 \mathrm{~kg}$ of green fodder.

Table.1: Showing day wise biomass yield $(\mathrm{kg})$ of different varieties of cereal and pulses under low cost hydroponic fodder production unit.

\begin{tabular}{|c|c|c|c|c|c|c|}
\hline \multirow{2}{*}{ Crop } & \multicolumn{6}{|c|}{ Day wise biomass yield (kg) } \\
\hline & Sprout weight & One day & Two days & Three days & Four days & Five days \\
\hline Maize & 1.08 & 1.46 & 2.07 & 2.36 & 4.1 & 4.82 \\
\hline Sorghum & 2.04 & 2.87 & 3.57 & 4.57 & 5.285 & 6.1 \\
\hline Bajra & 2.17 & 3.1 & 3.89 & 4.96 & 5.665 & 6.37 \\
\hline Barley & 1.98 & 2.69 & 3.37 & 4.21 & 4.635 & 5.06 \\
\hline Cowpea & 3.45 & 4.37 & 4.82 & 5.97 & 6.585 & 7.2 \\
\hline Lucerne & 3.22 & 4.46 & 5.38 & 5.89 & 6.49 & 7.09 \\
\hline Horse gram & 2.88 & 3.73 & 4.45 & 5.1 & 5.49 & 5.88 \\
\hline Pilli pesara & 3.26 & 4.07 & 4.62 & 5.96 & 6.77 & 7.58 \\
\hline Mean & 2.323 & 3.158 & $\mathbf{3 . 8 5 0}$ & 4.66 & 5.46 & 6.09 \\
\hline S.D. & 0.824 & 1.465 & 1.925 & 2.319 & 2.748 & 3.18 \\
\hline S.E. & 0.291 & 0.488 & 0.609 & 0.733 & 0.829 & 0.918 \\
\hline
\end{tabular}

\section{Plant height:}

The data recorded on day wise height of the plants of different cereal and pulse grains are given in table2. The data revealed that the highest height of the plants after 5 days in cereals was recorded in Barley $(18.4 \mathrm{~cm})$ followed by Maize $(18.1 \mathrm{~cm})$, sorghum $(10.8 \mathrm{~cm})$ and bajra $(7.9 \mathrm{~cm})$.
Among pulses Cowpea $(25.33 \mathrm{~cm})$ recorded highest height followed by pillipesara $(11.16 \mathrm{~cm})$, Lucerne $(8.56 \mathrm{~cm})$ and Horse gram $(7.46 \mathrm{~cm})$. The difference $(\mathrm{P}>0.05)$ among all the varieties in respect of plant height was found to be significant. Negative correlation was observed among biomass yield and plant height after five days.

Table.2: Showing day wise plant height (cm) of different varieties of cereal and pulses under low cost hydroponic fodder production unit.

\begin{tabular}{|l|r|r|r|r|r|}
\hline \multirow{2}{*}{ Crop } & \multicolumn{6}{|c|}{ Day wise plant height $(\mathbf{c m})$} \\
\cline { 2 - 6 } & One day & \multicolumn{1}{c|}{ Two days } & \multicolumn{1}{c|}{ Three days } & \multicolumn{1}{c|}{ Four days } & \multicolumn{1}{c|}{ Five days } \\
\hline Maize & 1.33 & 3.03 & 7.8 & 11.33 & 18.1 \\
\hline Sorghum & 0.53 & 1.76 & 2.26 & 4.36 & 10.8 \\
\hline Bajra & 0.6 & 2.26 & 3.9 & 5.26 & 7.9 \\
\hline Barley & 1.53 & 2.36 & 4.53 & 7.26 & 18.4 \\
\hline Cowpea & 2.91 & 6.13 & 7.63 & 10.43 & 25.33 \\
\hline Lucerne & 1.86 & 2.56 & 2.46 & 2.73 & 8.56 \\
\hline Horse gram & 0.6 & 2.86 & 4.86 & 5.4 & 7.46 \\
\hline Pilli pesara & 1.53 & 2.76 & 3.9 & 5.63 & 11.16 \\
\hline Mean & $\mathbf{1 . 3 6}$ & $\mathbf{2 . 9 6}$ & $\mathbf{4 . 6 6}$ & $\mathbf{6 . 5 5}$ & $\mathbf{1 3 . 4 6}$ \\
\hline S.D. & 0.807 & 1.253 & 2.087 & 2.967 & 6.438 \\
\hline S.E. & 0.285 & 0.418 & 0.738 & 1.049 & 2.276 \\
\hline
\end{tabular}




\section{CONCLUSIONS}

Low cost hydroponic fodder production technology play key role in intensive fodder production especially for land less dairy farmers. Cereals and Pulses can be successfully grown for fodder in low cost hydroponic system. Among the cereals Bajra and in pulses Pillipesara recorded highest bio mass within five days. Significant and positive correlation was found between sprout weight and bio mass yield among all the grains and difference among all the varieties in respect of biomass yield was found to be significant at 5\% level. Among cereals Barley and pulses cowpea recorded highest plant height after five days. Negative relation was observed among biomass yield and plant height after five days.

\section{REFERENCES}

[1] Brunean M.M., Grondin S. and Benard J.L. (2016) Feeding of hydroponic barley fodder to thin heifer before initial breeding, Compendium of International Conference of ISAPM, 2016 pp.226-236.

[2] Naik P.K., Swain B.K. and Singh N.P. (2015) Production and utilization of Hydroponic Fodder, Indian J.Anim. Nutr.2015, 32(1). 